- In 2002, the BDJ was the most popular journal for finding a job, reports on research and recruiting an employee.

- The most frequently read sections of the BDJ in 2002 were 'News' and 'Research summaries'.

- The website appears to be becoming more popular: over half (57\%) of survey respondents in 2002 accessed the $B D$ J website occasionally.

\title{
What do readers want from their journal? BDJ readership survey 2002
}

\author{
J. C. Stott ${ }^{1}$
}

In July 2002 a survey was carried out to determine readers' views on the British Dental Journal. A response rate of 59\% was achieved. This survey followed similar research carried out in 1992, ${ }_{1}^{1995}{ }_{1}{ }^{2} 1997^{3}$ and $1999,{ }_{1}{ }^{4}$ and the same questions were asked in order to allow comparisons. The full findings of the survey are reported here.

The questionnaire was sent to a random sample of 1,000 BDA members from all fields of dentistry, excluding students, overseas and retired members. In total, 587 usable questionnaires were received, giving a response rate of 59\% and making any non-response bias low. The survey response by gender, year of qualification and field of dentistry was representative of BDA membership as a whole and the results were therefore considered to be reliable. The questionnaire was very similar to that used in previous years and included questions about journal reading, the usefulness of $B D J$ sections, subject coverage and the $B D J$ website. The majority (74\%) of survey respondents worked in general dental practice: $71 \%$ in general practice and 3\% in general practice within a corporate body. Sixteen percent of those in general practice worked in single-handed practices. These results were very similar to those observed in 1999. In 2002, 55\% of respondents working in general practice

\footnotetext{
${ }^{1}$ Policy Development Officer, Policy Research Unit, British Dental Association

Correspondence to: Claire Stott, Policy Directorate, British Dental Association, 64 Wimpole Street, London W1G 8YS Email: c.stott@bda-dentistry.org.uk
}

earned more than three quarters of their income from NHS work, compared with 58\% in 1999 and 61\% in 1997. Results from the 2002 survey showed that the typical $B D J$ reader was between 30 and 50 years old (58\%), male (60\%) and married $(71 \%)$. The percentage of female respondents in 2002 (40\%) was higher than in 1999 (29\%). The typical survey respondent had either two children (31\%) or none (36\%) and listened to classical $(29 \%)$ or modern pop (21\%) music.

\section{JOURNAL READING GENERALLY}

Readers were asked to indicate how many issues they read out of a list of ten dental journals, including the $B D J$ and $B D A$ News. When interpreting these results it should be remembered that BDA mem- bership includes subscriptions to both the $B D J$ and $B D A$ News. Table 1 shows the 2002, 1999 and 1997 percentages of respondents reading 'every' or 'most' issue(s) of each journal listed. In previous years Primary Dental Care was not included on the list. In 1995 and 1992 the question was phrased slightly differently and asked respondents how much of each journal they read, rather than how many issues. The percentages of survey respondents reading every/most issue(s) of the BDJ (91\%) and BDA News (87\%) remained high in 2002. The percentage of respondents reading every/most issue(s) of Dentistry (previously Dentistry Monthly) increased to 49\% in 2002 (compared with only $22 \%$ in 1999). In contrast, the percentages of respondents

Table 1 Percentage of respondents reading every/most issue(s) of each journal

\begin{tabular}{llcc}
\hline \% respondents & 2002 & 1999 & 1997 \\
\hline British Dental Journal & $\mathbf{9 1}$ & $\mathbf{9 0}$ & $\mathbf{9 0}$ \\
BDA News & $\mathbf{8 7}$ & $\mathbf{8 7}$ & $\mathbf{8 8}$ \\
Dental Practice & 56 & 60 & 70 \\
The Dentist & 50 & 43 & 50 \\
Dentistry (previously Dentistry Monthly) & $\mathbf{4 9}$ & $\mathbf{2 2}$ & $\mathbf{2 4}$ \\
Dental Update & 46 & 47 & 47 \\
The Probe & 43 & 48 & 54 \\
Independent Dentistry & 28 & 18 & 23 \\
Primary Dental Care & 18 & -- & -- \\
The General Dental Practitioner & 14 & 20 & 29
\end{tabular}


Table 2 Journals considered to be most useful for each topic

\begin{tabular}{l|lllll|l}
\hline \% respondents & \multicolumn{7}{|c}{$\%$ choosing BDJ first } & ' & 2002 1st choice \\
& '02 & '99 & 97 & 95 & '92 & if not BDJ (\%) \\
\hline Finding a job & $\mathbf{9 4}$ & $\mathbf{9 7}$ & $\mathbf{9 8}$ & $\mathbf{9 9}$ & $\mathbf{1 0 0}$ & -- \\
Reports on research & $\mathbf{8 3}$ & $\mathbf{8 9}$ & $\mathbf{9 4}$ & $\mathbf{8 6}$ & $\mathbf{8 7}$ & -- \\
Recruiting an employee & $\mathbf{8 2}$ & $\mathbf{8 8}$ & $\mathbf{8 4}$ & $\mathbf{9 7}$ & $\mathbf{9 9}$ & -- \\
Opinion/debate/letters & 65 & 69 & 66 & 57 & -- & -- \\
Oral health promotion/ policy & 50 & 53 & 50 & 44 & -- & -- \\
Keeping up to date clinically & 41 & 40 & 57 & 41 & 22 & -- \\
Product news & 29 & 27 & 20 & 16 & -- & -- \\
Staff training & 25 & 26 & 27 & 29 & 36 & -- \\
Dental business & 23 & -- & -- & -- & -- & -- \\
Political/employment topics & $\mathbf{2 1}$ & $\mathbf{3 1}$ & $\mathbf{2 6}$ & $\mathbf{1 7}$ & $\mathbf{1 1}$ & BDA News (64) \\
Practice management & 14 & 10 & 6 & 8 & 3 & The Dentist (26) \\
Financial management & 12 & 10 & 6 & 8 & 1 & The Dentist(23)
\end{tabular}

reading some of the other journals (Dental Practice, The Probe and The General Dental Practitioner) decreased, suggesting that readers were becoming more selective.

Readers were asked to rate which of the journals they considered to be the most useful for each of 11 topics. The percentage of respondents choosing the $B D J$ first for each topic is shown in Table 2. Also shown is the 2002 first choice for each topic if it was not the $B D J$. Percentages since 1992 are also shown. The BDJ remained the first choice for finding a job, reports on research and recruiting an employee, but the majority (64\%) of respondents preferred $B D A$ News for political/employment topics. This was also the case in 1999, 1997, 1995 and 1992. The Dentist has remained the first choice for practice management since 1992. In 2002, The Dentist was also the preferred journal for financial management (as in 1995 and 1992).

\section{$B D J$ READING AND USEFULNESS}

Readers were asked how often they read 14 different $B D J$ sections. Table 3 shows

how the percentage of respondents reading each section always or sometimes, with results from previous years for comparison. Readers were also asked to rate the usefulness of each $B D J$ section, using a scale of 1 ('not useful') to 4 ('useful'). Table 3 also shows the percentage of respondents rating each section useful (an amalgamation of scores 3 and 4). In 2002, the most frequently read section of the $B D J$ was 'News', followed by 'Research summaries' (not listed as an option in previous years). 'Case reports' and 'Classified ads' remained popular, but the proportion reading 'Letters to the Editor’ has fallen steadily since 1992.

\section{BDJ SUBJECT COVERAGE}

Readers were asked if more or less $B D J$ coverage was needed of 17 subjects. Readers thought there should be more coverage of practical clinical techniques and 'How to do it' articles and fewer nondental topics. These findings are similar to those observed in previous years. The 2002 results indicated that readers would like more coverage of materials research. This was a change since 1999, when they
Table 3 BDJ section reading

\begin{tabular}{l|lllll|lllll|r}
\hline \% respondents & \multicolumn{5}{|c|}{ Always read } & \multicolumn{5}{c|}{ Sometimes read } & \% useful \\
\hline News & '02 & '99 & '97 & '95 & '92 & '02 & '99 & '97 & '95 & '92 & 2002 \\
\hline Research summaries & $\mathbf{5 2}$ & $\mathbf{5 3}$ & $\mathbf{5 4}$ & $\mathbf{5 4}$ & $\mathbf{5 5}$ & $\mathbf{4 5}$ & $\mathbf{4 4}$ & $\mathbf{4 2}$ & $\mathbf{4 4}$ & $\mathbf{4 2}$ & $\mathbf{7 7}$ \\
Case reports & $\mathbf{4 3}$ & -- & -- & -- & -- & $\mathbf{5 4}$ & -- & -- & -- & -- & $\mathbf{7 5}$ \\
Classified ads & 42 & 41 & 45 & 52 & 39 & 57 & 58 & 54 & 57 & 56 & 77 \\
Letters to the editor & 37 & 36 & 37 & 38 & 36 & 53 & 55 & 52 & 49 & 52 & 65 \\
Leader & $\mathbf{3 6}$ & $\mathbf{4 8}$ & $\mathbf{5 0}$ & $\mathbf{5 2}$ & $\mathbf{5 6}$ & $\mathbf{5 6}$ & $\mathbf{4 7}$ & $\mathbf{4 6}$ & $\mathbf{4 6}$ & $\mathbf{3 9}$ & $\mathbf{6 5}$ \\
Abstracts & 33 & 36 & 34 & 31 & 36 & 60 & 58 & 60 & 59 & 55 & 56 \\
Education & 28 & 27 & 21 & 23 & 19 & 65 & 65 & 63 & 63 & 60 & 74 \\
Research papers & 26 & 25 & -- & -- & -- & 66 & 69 & -- & -- & -- & 71 \\
Obituaries & 24 & 25 & -- & -- & -- & 69 & 71 & -- & -- & -- & 67 \\
Practice papers & 22 & 23 & 26 & 28 & -- & 55 & 59 & 62 & 51 & -- & 28 \\
"Trade news" & 19 & -- & -- & -- & -- & 68 & -- & -- & -- & -- & 63 \\
Product ads & 15 & 18 & 16 & 17 & 15 & 67 & 68 & 68 & 63 & 62 & 48 \\
Book reviews & 11 & 16 & 10 & -- & -- & 74 & 72 & 74 & -- & -- & 52
\end{tabular}

wanted less, but the same opinion as in 1997. In 1995 and 1992 coverage of this was about right. The 2002 survey indicated that $B D J$ coverage of UK meetings and events, abstracts from other journals and oral health promotion was about right. This was also the case in previous years. In 1999, readers indicated that they would like less coverage of political news. In 2002 the coverage was about right (as in 1997, 1995 and 1992).

\section{READING PATTERNS}

In addition to asking about $B D J$ sections, the survey asked members about their $B D J$ reading patterns. Forty two percent of survey respondents had been reading the $B D J$ for 20 years or more. This is roughly the same proportion as in previous years (43\% in 1999 and 42\% in 1997). Seventy one percent of respondents spent between 15 and 60 minutes reading the $B D J$. This is less than in 1999 $(83 \%)$ and 1997 (82\%). The results indicated that $21 \%$ of respondents spent over an hour reading the $B D J$. This is an increase on the 1999 (7\%) and 1997 (9\%) figures. The proportion of respondents reading half or more of the journal has remained about the same since 1997 (67\% in 2002 compared with 64\% in 1999 and 63\% in 1997). Similarly, the proportion filing the entire journal for future reference has not changed greatly since 1997 (50\% in 2002 compared with $46 \%$ in 1999 and 48\% in 1997). Of those filing the entire journal for future reference, 56\% said that they kept it for more than 3 years. Again, this is similar to the results seen in 1999 (52\%) and 1997 (55\%). The survey revealed that $68 \%$ of respondents lent their $B D J$ to at least one other person.

\section{BDJ WEBSITE}

Readers were asked about the $B D J$ website (www.bdj.co.uk). Most respondents (57\%) accessed the $B D J$ website occasionally (compared with 35\% in 1999) and 39\% never accessed it at all (compared with 62\% in 1999). In 2002, the most frequently viewed sections on the website were 'Research', 'Summaries', 'Practice section' and 'News and notes'. This was also the case in 1999. GDPs were more likely than non-GDPs to view the 'Practice section'. As might be expected, more recently qualified dentists were more likely to access the website at all. The most popular sections viewed by dentists qualified after 1992 were 'Research' and the 'Classified section'. Men were more likely than women to view the 'Leader', 'Letters' or 'Practice section'. 


\section{BDJ ADVERTISING}

The survey also asked members about their hobbies and interests. This was to assist the $B D J$ in choosing appropriate products to advertise and included questions such as 'What kind of car do you drive?' and 'What type of music do you primarily listen to?' For interest, the responses to these questions have been grouped into categories and are shown in Tables 4 and 5.

\section{CONCLUSION}

In conclusion, the majority of survey respondents read every/most issue(s) of the $B D J$ and BDA News. In 2002, the BDJ was the most popular journal for finding a job, reports on research and recruiting an employee, but BDA News was preferred for political/employment topics. The most frequently read sections of the $B D J$ in 2002 were 'News' and 'Research summaries'. Overall, readers wanted more coverage of practical clinical techniques and 'How to do it' articles and less coverage of non-dental

\begin{tabular}{llllll}
\multicolumn{2}{l}{ Table } & What & kind of car do you drive? & (\% respondents) \\
\hline Audi & 6 & Mercedes & 6 & Nissan/Mazda & 4 \\
BMW & 8 & Peugeot & 6 & Rover/Nauxhall & 8 \\
Ford & 7 & Toyota & 5 & Volvo/Saab & 9 \\
Honda & 4 & Volkswagen & 12 & Jaguar/Porsche & 2 \\
Land Rover & 5 & Citroen/Renault & 8 & Other & 11
\end{tabular}

\begin{tabular}{llll} 
Table $\mathbf{5}$ What type of music do you primarily listen to? (\% respondents) & \\
\hline Classic rock/pop & 11 & Jazz/blues/indie & 9 \\
Classical & 29 & Modern pop & 21 \\
Country/folk & 2 & Radio 2 & 4 \\
Easy listening & 5 & Variable & 14 \\
Contemporary/dance & 2 & Other & 2
\end{tabular}

topics. $B D J$ coverage in 2002 of UK meetings and events, abstracts from other journals and oral health promotion was considered to be about right. Finally, the website appears to be becoming more popular: over half (57\%) of survey respondents in 2002 accessed the $B D J$ website occasionally

1. Morris S. Readership survey results Br Dent J 1993; 174: 144-145.

2. Desmond J. Results of the readers' survey Br Dent J 1995; 180: 193-194

3. Desmond J. BDJ readership survey Br Dent J 1998; 184: $563-564$

4. Desmond J. BDJ readership survey Br Dent J 2000; 188: $233-234$

\section{A change in recording tooth notation}

The BDJ has traditionally adopted the Palmer tooth notation as the first choice for recording individual teeth in papers and articles. This system, very familiar to dentists in the UK, is reproduced below for both adult and deciduous teeth.

\begin{tabular}{|c|c|}
\hline 87654321 12345678 & \begin{tabular}{l|l} 
EDCBA & $A B C D E$ \\
\end{tabular} \\
\hline \begin{tabular}{l|l}
87654321 & 12345678 \\
\end{tabular} & \begin{tabular}{l|l} 
EDCBA & $A B C D E$
\end{tabular} \\
\hline
\end{tabular}

We recently changed the actual way the Palmer system is written because of difficulties converting the familiar grid format to our website. Instead the position on the grid is now written using the shorthand UR for upper right, UL for upper left, LL for lower left and LR for lower right.

Thus 7 becomes UR7 and $\sqrt{5}$ is written as LL5. Groups of teeth will be recorded as best we can, so for example 54 will become UR5 and UR4, while 2345 will be written as UL2 to UL5.

Obviously the same will apply to deciduous teeth, for example E will be written as URE.

The FDI notation will still be written in brackets after the Palmer notation, using the familiar FDI notation as described below:

\begin{tabular}{ll|l|l|l|l}
1817161514131211 & 2122232425262728 for adult teeth
\end{tabular}

\begin{tabular}{ll|l}
4847464544434241 & 3132333435363738
\end{tabular}

and

\begin{tabular}{l|ll}
5554535251 & 6162636465 \\
\hline 8584838281 & 7172737475
\end{tabular} for deciduous teeth

Thus using both systems, 7] will be written as UR7 (17) and $\sqrt{5}$ will become LL5 (35). 